\title{
Spillway blockage caused by large wood in reservoirs
}

\author{
Paloma Furlan ${ }^{1,2,}$, Michael Pfister ${ }^{3}$, Jorge Matos $^{2}$, and Anton J. Schleiss ${ }^{1}$ \\ ${ }^{1}$ Laboratory of Hydraulic Constructions (LCH), Ecole Polytechnique Fédérale de Lausanne, Lausanne, \\ Switzerland \\ ${ }^{2}$ CERIS, Instituto Superior Técnico, Universidade de Lisboa, Lisboa, Portugal \\ ${ }^{3}$ Haute école d'ingénierie et d'architecture Fribourg (HEIA), HES-SO, Switzerland
}

\begin{abstract}
Large wood (LW) elements are often transported by rivers into reservoirs during heavy rainfall events. Large wood has important environmental attributes that benefit the diversification of riverine ecosystems. There are several studies dealing with the transport and behaviour of LW inside streams. However, during flood events, LW tends to create jams or blockages at diverse hydraulic structures inside streams, creating significant problems such as discharge limitations and increased water levels. Even though knowledge on the effect of LW at bridges in rivers with relatively high flow velocities starts to be available, the latter is hardly applicable for reservoir approach flow conditions. Understanding LW blockage processes at a reservoir spillway is essential regarding the safety evaluation of a dam and the surrounding areas. The geomorphologic benefits of wood for stream restoration depends also on our present ability to manage jams and the risk they imply for civil structures when blocked. Therefore, series of systematic laboratory experiments were conducted to analyse blockage of floating stems at an ogee crested spillway equipped with piers. Different LW characteristics were represented in a physical model with cylindrical stems. Results associate the size of stem groups to blockage probabilities and the effect blockages can have on the discharge capacity of a spillway.
\end{abstract}

\section{Introduction}

The mobilization of woody debris into streams is frequent in forested areas due to heavy rainfall events, windfall, landslides or erosion of the shores. Once the woody material is inside a riverine stream, it can have different types of interactions with hydraulic structures. Nonetheless, the effects of those interactions seen throughout history are hazardous and unsafe for the normal functioning of hydraulic structures.

Spillways are elements of dams designed to lead safely floods downstream so that the dam integrity is not endangered. The blockage of large wood (where large wood (LW) is defined as stems longer than $1 \mathrm{~m}$ and larger than $0.10 \mathrm{~m}$ in diameter [1-3]) at bridges or spillway inlets can induce important forces to the structure and endanger their stability and safety. During a single event, the degree of blockage may vary from a single piece blocked across the inlet to a fully blocked structure.

Interactions among multiple LW pieces can either increase or decrease blocking probabilities: piece-to-piece collisions can drag previously blocked pieces, while immobile pieces can obstruct moving pieces, causing blockage and formation of jams. If a blockage starts to develop at a spillway inlet, the reduction of the spillway capacity may result in a

* Corresponding author: paloma.furlan@epfl.ch 
dangerous backwater rise upstream of the structure [4-5] with the risk of uncontrolled overtopping.

Considering the important consequences a blockage of spillway can have, the probabilities of blocking must be systematically quantified in order to identify the damage potential of LW. Once the spillway is blocked with LW, measurements of backwater rise are important estimators for safety assessment. Tests were performed in a laboratory facility to estimate blockage probabilities of artificial stems at an ogee crested spillway with piers and its effect on the rating curve of the spillway.

\section{Model set-up}

An experimental facility was developed for this research at the Laboratory of Hydraulic Constructions (LCH) of École Polytechnique Fédérale de Lausanne (EPFL), Switzerland. The channel was $1.50 \mathrm{~m}$ wide and $10 \mathrm{~m}$ long with a rectangular cross-section (Figure 1). The physical model was composed of an ogee crested spillway with round-nose piers. There were five fully open bays. The nose of the piers had a $0.04 \mathrm{~m}$ intrusion in the upstream face of the spillway. The model was built with plastic materials to be considered hydraulically smooth.

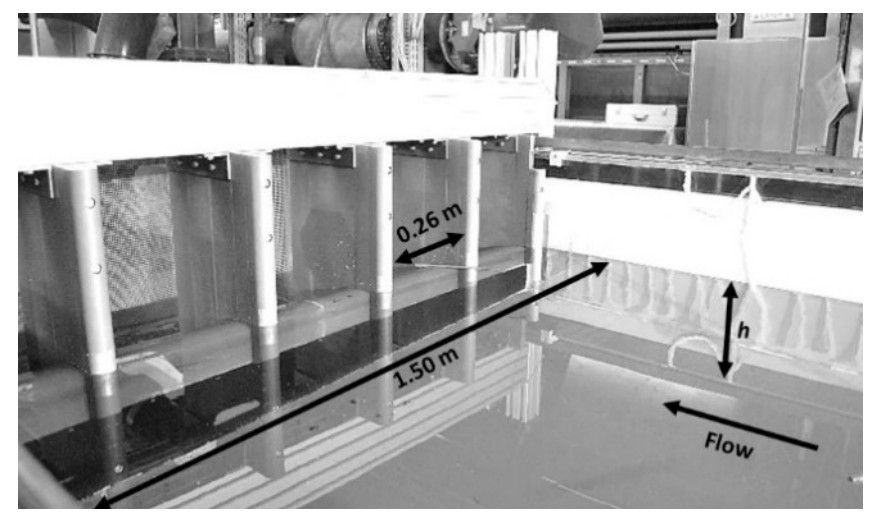

Figure 1: Picture of the upstream face of the spillway with five open bays.

The level of water in the channel (reservoir) $h(\mathrm{~m})$ was measured with a point gauge $( \pm 0.5$ $\mathrm{mm})$ and an ultrasonic distance sensor $( \pm 0.3 \mathrm{~mm}), 2.60 \mathrm{~m}$ upstream of the ogee. The discharge $Q\left(\mathrm{~m}^{3} / \mathrm{s}\right)$ was measured with a magnetic inductive flow meter $( \pm 0.5 \%$ at full $\mathrm{span})$. The head $H(\mathrm{~m})$ was calculated based on the level measurements and the kinematic head. Small magnitudes of reservoir flow velocity were used to represent a reservoir approach.

\subsection{Artificial stems}

Due to impacts against rocks or other objects, LW inside a stream tends to lose its branches, rootstocks and foliage. Therefore, a pragmatic geometry was chosen to represent LW through cylindrical stems with constant dimensions (Table 1).

Table 1: Artificial stems characteristics.

\begin{tabular}{|c|c|c|c|c|}
\hline Class & $\boldsymbol{L}(\mathbf{m})$ & $\boldsymbol{L} / \boldsymbol{b}(-)$ & Stem density $\boldsymbol{\rho}_{\boldsymbol{s}}\left(\mathbf{t} / \mathbf{m}^{\mathbf{3}}\right)$ & $\boldsymbol{d}(\boldsymbol{m})$ \\
\hline A & 0.21 & 0.80 & 0.59 & 0.010 \\
\hline C & 0.30 & 1.20 & 0.56 & 0.016 \\
\hline E & 0.52 & 2.00 & 0.54 & 0.025 \\
\hline
\end{tabular}


Stems were fabricated with plastic materials assuring constant weight during the experiments. The density of the artificial stems ranged within $0.56 \pm 0.03 \mathrm{t} / \mathrm{m}^{3}$, similar to the average density of dry wood in Europe [6]. More information about the influence of the density effect for blockage probability estimations can be seen in [7]. Stems were divided into different classes based on their relative length (length of stem $L(\mathrm{~m})$ divided by the opening of the spillway bay $b(\mathrm{~m})$ ). The slenderness and relative lengths were defined based on the data collected for blocked stems at bridges in Switzerland after a flood [8] and the experiments previously done in [9]. The stem relative length of 0.80 was chosen specifically as it is one of the recommendations for spillway constructions from [10] in order to have blockages smaller than $20 \%$.

\subsection{Methodology}

Series of experiments were performed systematically. At the beginning of an experiment, the water surface level and discharge were measured without stems. With a mechanical equipment, a group of stems was supplied inside the channel in the centre line oriented parallel to the flow. Once the stems arrived at the spillway, notes were taken of how many stems blocked and passed. Subsequently, the blocked stems were removed and a new repetition of the experiment was performed. Several repetitions were done per experiment with constant initial conditions for statistical accuracy. Table 2 shows the table of experiments with the combination of parameters tested.

Table 2: Table of experiments

\begin{tabular}{|c|c|c|c|c|}
\hline Exp. $\mathrm{N}^{\circ}$ & Class & $H / d(-)$ & Group size $G_{i}(-)$ & Experiment repetitions (-) \\
\hline 1 & \multirow{2}{*}{ A } & 1.00 & $1 ; 2 ; 4 ; 8 ; 16 ; 32$ & $30 ; 15 ; 8 ; 4 ; 3 ; 3$ \\
\hline 2 & & 1.20 & $1 ; 2 ; 4 ; 8 ; 16 ; 32$ & $30 ; 15 ; 8 ; 4 ; 3 ; 3$ \\
\hline 3 & \multirow{2}{*}{$\mathrm{C}$} & 0.94 & $1 ; 2 ; 4 ; 8 ; 16 ; 32$ & $30 ; 15 ; 8 ; 4 ; 3 ; 3$ \\
\hline 4 & & 1.06 & $1 ; 2 ; 4 ; 8 ; 16 ; 32$ & $30 ; 15 ; 8 ; 4 ; 3 ; 3$ \\
\hline 5 & \multirow{2}{*}{$\mathrm{E}$} & 0.76 & $1 ; 2 ; 8 ; 16 ; 32$ & $30 ; 15 ; 4 ; 3 ; 3$ \\
\hline 6 & & 0.84 & $1 ; 4 ; 8 ; 16 ; 32$ & $30 ; 8 ; 4 ; 3 ; 3$ \\
\hline
\end{tabular}

To analyse the influence of the group size for blocking probabilities estimations, different homogeneous groups of stems were tested, being defined as $G_{i}=2^{\text {n }}$, where $n=0 ; 1 ; 2 ; 3 ; 4 ; 5$. In an experiment, $H$ and stem class were kept constant while changing systematically the number of supplied stems (group size). The blockage probability was estimated as the ratio of stems blocked versus total number of stems supplied, averaging the estimation for all the repetitions. For example: for groups of 2 stems, it was noted the number of stems that blocked and divided by 2 , after the 15 results were averaged. Figure 2 shows some examples of the experiments performed where different group sizes are being evaluated. 
A

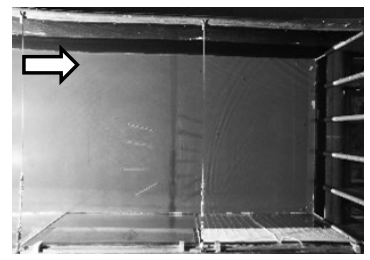

$\mathrm{C}$

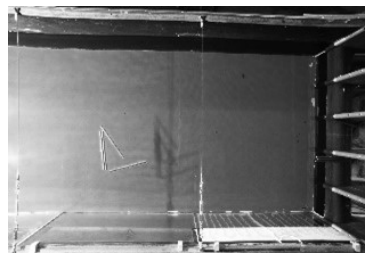

E

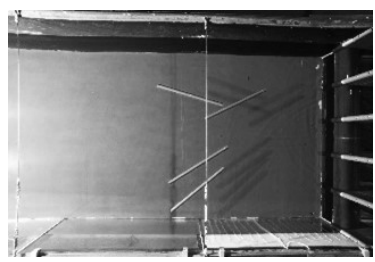

Group 4
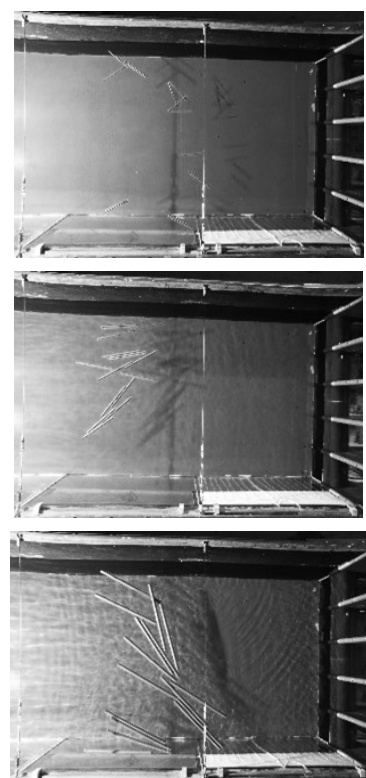

Group 16
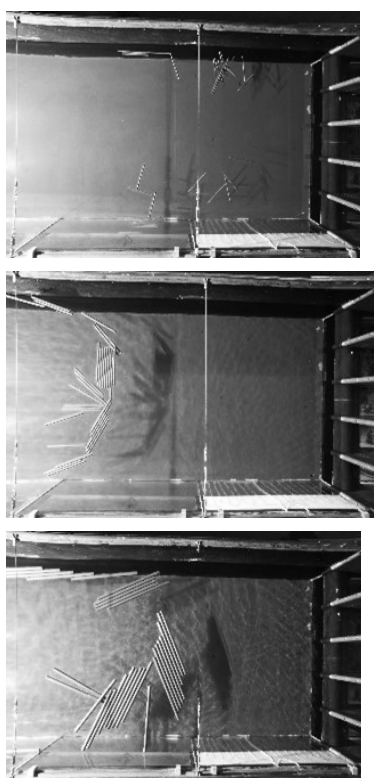

Group 32

Figure 2: Pictures of experiments taken from above the model, water flows from left to right.

To evaluate the effect of a blockage on the rating curve, the experiments of Table 2 were used as initial conditions. Groups of stems were manually arranged at the spillway inlet in different directions and the surface water level was measured after 5 minutes, three consecutive times. Only the results obtained from blocked stems parallel to the flow direction (Figure 3) are discussed in this article as they adequately explain the process observed in the group size experiments. Experiments with blocked stems perpendicular to the flow direction were evaluated but as the pier nose protrudes the upstream face of the spillway, stems would not reach the spillway crest, creating a carpet upstream the structure without affecting the rating curve. Due to the movement of the stems at the inlet, these experiments were considered only qualitatively.

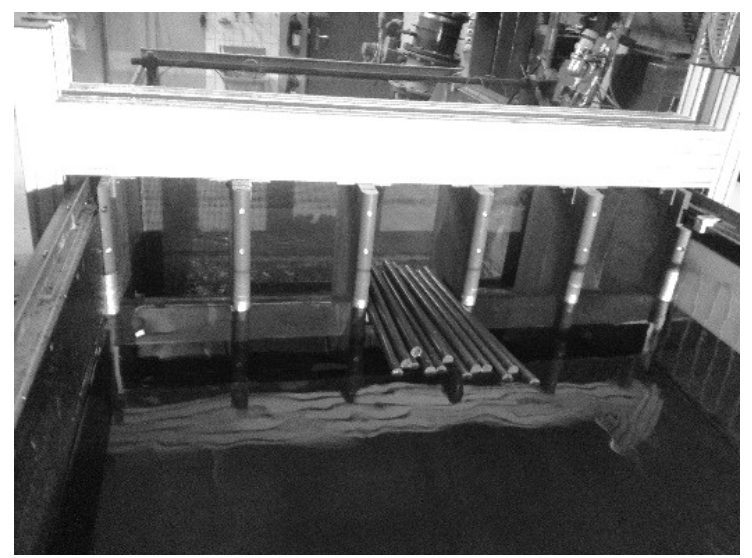

Figure 3: Picture of experiment 5 (Table 2), group size $G_{16}$ for measuring head increase. 


\section{Results}

Blocking probabilities $\widehat{\Pi}$ were estimated as the number of stems blocked divided by the number of stems supplied. An averaged value of the blocking probability was taken from the repetitions.

The effects of different group sizes for the blocking probability estimation can be seen in Figure 4. Comparing the blocking probability estimations, it can be seen that an increase of $H / d$ represents a decrease of the estimated blocking probability. This is detectable from experiment 1 to $2 ; 3$ to 4 ; and 5 to 6 .

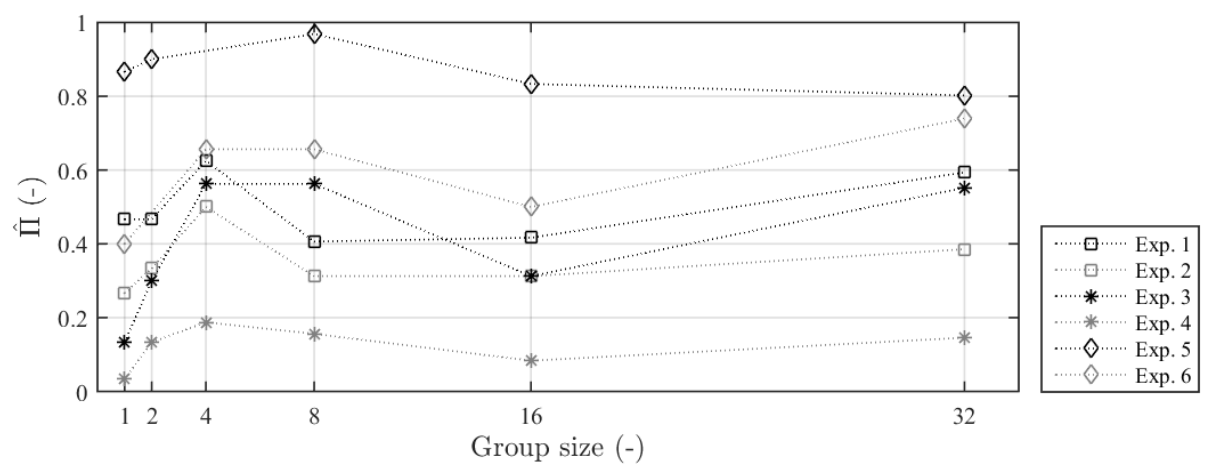

Figure 4: Blocking probability estimation for different group sizes.

For experiments 1 and 2, the change of the group size tends to have similar influence on the blockage estimation regardless $H / d$. As the group size is increased from $G_{l}$ to $G_{4}$, the blockage probability is increased. When comparing $G_{4}$ against $G_{8}$, it can be seen that the probability decreases and remains constant until $G_{16}$. From groups $G_{16}$ to $G_{32}$ there is an increment of $\Delta \widehat{\Pi}=0.18$ in experiment 1 and $\Delta \widehat{\Pi}=0.07$ in experiment 2 .

For experiment 3 and 4, similar behaviour of $\widehat{\Pi}$ was observed between $G_{l}$ and $G_{4}$. As the group size was increased, the blockage probability was increased. Although the slope of increment of the blockage probability is different. In experiment $3, \widehat{\Pi}_{1}=0.13$ and $\widehat{\Pi}_{4}=0.56$ resulting in a $\Delta \widehat{\Pi}=0.43$ and in experiment $4, \widehat{\Pi}_{1}=0.03$ and $\widehat{\Pi}_{4}=0.18$ resulting in a $\Delta \widehat{\Pi}=$ 0.15 . The different slope might be related to the tested $H / d$. Experiment 3 , from $G_{4}$ to $G_{8}$ had constant blocking probability, decreasing for $G_{16}$ and increasing again for $G_{32}$. It was noted that $G_{32}$ had a similar blockage probability $(\Delta \widehat{\Pi}<0.05)$ than $G_{4}$ and $G_{8}$. Experiment 4 showed trends alike experiment 3 but with smaller $\Delta \widehat{\Pi}$.

Experiments 5 and 6 had smaller changes of the blockage probability when the group size was increased. Probabilities increased from $G_{1}$ to $G_{8}$, decreased from $G_{8}$ to $G_{16}$ and remained partially constant or increased again for $G_{32}$.

A preliminary analysis was made on the head increase experiments as a function of the group size of blocked stems. It was noticed that experiments 5 and 6 seemed to have a local maximum value for the head increase (Figure 5). Polynomial functions were fitted to the results obtained to help visualizing the results. For experiments 1 and 2, if a local maximum head increment exists, it was not noticeable from the experiments performed. As for experiment 3, larger groups should be tested to evaluate if a maximum value of head increment exists near $G_{32}$. Experiment 4 shows a similar trend than experiment 2, thus more experiments should be performed. To verify these trends and the adequacy of the fitted polynomial functions, a more complete set of experiments should be undertaken. 

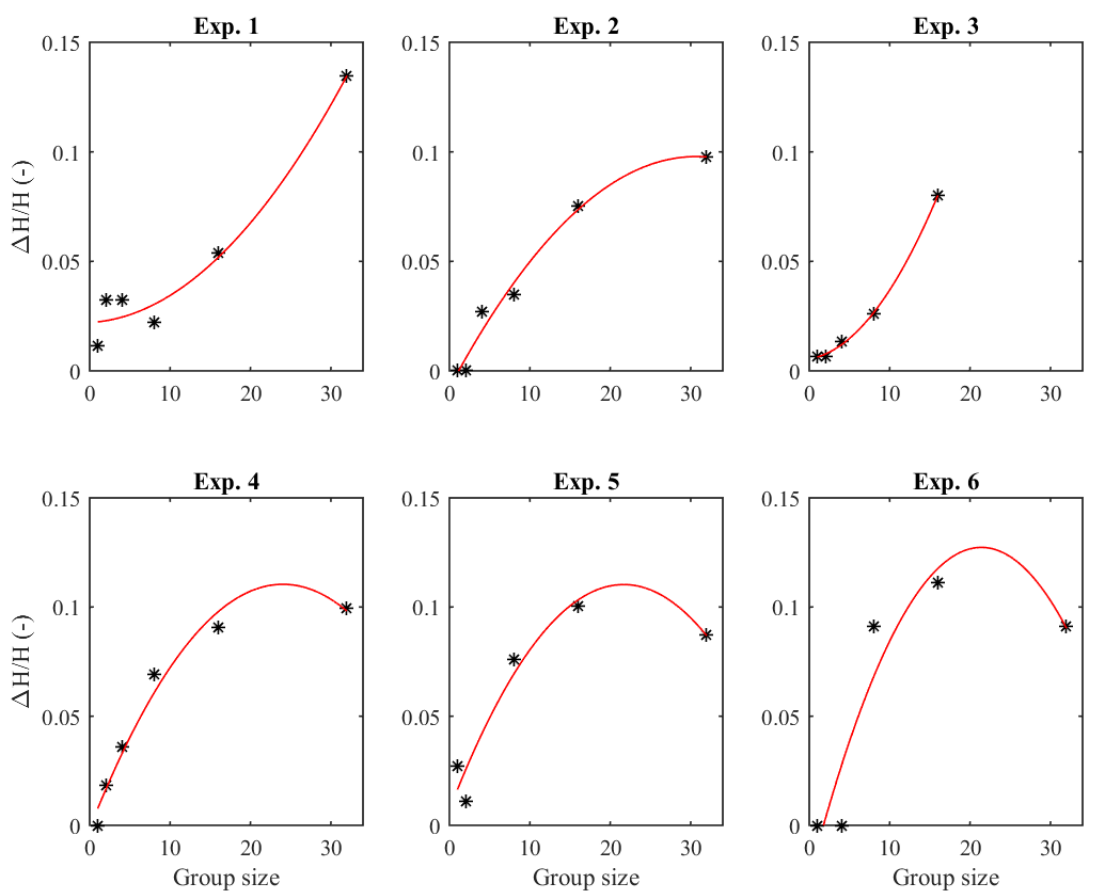

Figure 5: Measured head increase as a function of group size.

As part of a preliminary analysis, the decrease of the blockage probability when passing from $G_{8}$ to $G_{16}$ (seen in experiment 3-6) can be related to the maximum change in the head due to blocked stems at the inlet. This relation goes in agreement with the observations of higher blockages for $G_{32}$ in comparison to $G_{16}$.

\section{Conclusions}

A broad and systematic experimental campaign has been carried out to study blocking probabilities of groups of stems at an ogee crested spillway with piers. To do so, different discharges have been tested for varying dimensions of artificial cylindrical stems and sizes of stem-groups. Measurements of the head increase due to a blockage of stems at the spillway inlet have been performed.

The blocking probability of stems, regardless of group size (i.e., number of stems per group), was demonstrated to increase with decreasing head at the spillway inlet. For the different dimensions of stems tested, blockage always increased with smaller $H / d$ relations. Blocking probabilities are linked also to the size of the stem group travelling together towards the structure. For groups up to 4 stems, the blocking probability increases as the size of the group increases. It was observed, in some experiments, that the blockage probability of 4 stems could be more than the double of the probability for one single stem under the same hydraulic conditions. The changes of blocking probabilities observed for stem groups between 8 and 32, can be related to the changes observed in the head due to the reduced spillway capacity. As the head in the reservoir tends to increase, the blocking probabilities decrease. There might be a maximum value of the head increase in function of the group size of blocked stems that will be further studied. 
This project is supported by "Fundação para a Ciência e a Tecnologia" (FCT) from Portugal (PD/BD/52664/2014) under IST - EPFL joint PhD initiative H2Doc. Further support was provided by the Laboratory of Hydraulic Constructions (LCH, EPFL) Switzerland, and Électricité de France (EDF) under contract No. 5500-5920006472. The authors would like to thank the assistance of Selene Hewes for her contribution during a semester project at EPFL.

1. C.A. Braudrick, G.E. Grant, Y. Ishikawa, H. Ikeda, ESPL, 22, 669-683 (1997)

2. V. Ruiz-Villanueva, H. Piégay, A.M. Gurnell, R.A. Marston, M. Stoffel, Rev Geophys, 54, 611-652 (2016)

3. E. Wohl, B.P. Bledsoe, K.D. Fausch, N. Kramer, K.R. Bestgen, M.N. Gooseff, JAWRA, 52, 315-335 (2016)

4. L. Schmocker, W. Hager, J. Hydraul. Eng., 139, 827-836 (2013)

5. N. Johansson, M. Cederström, Proceedings of the International Conference on Hydropower - Waterpower '95. July 25-28. San Francisco, California. American Society of Civil Engineers, 2106-2115 (1995)

6. J. Chave, D. Coomes, S. Jansen, S.L. Lewis, N.G. Swenson, A.E. Zanne, Ecol Lett, 12, 351-366 (2009)

7. P. Furlan, M. Pfister, J. Matos, A.J. Schleiss, Proceedings of Colloque CFBR-SHF, Hydraulique des barrages et des digues, 29-30 novembre 2017, Chambéry, France. Société hydrotechnique de France, 42-49 (2017)

8. G.R. Bezzola, C. Hegg, Ereignisanalyse Hochwasser 2005, Teil 1 - Prozesse, Schäden und erste Einordnung [Event analysis flood 2005, Part 1 - Processes, damage and risk classifications](Technical Report No 0707) (2007)

9. A. Hartlieb, Proceedings of the 2nd IAHR Europe Congress, 27-28 June 2012, München, Germany, Paper C18 (2012)

10. K. Godtland, E. Tesaker, Proceedings of Commission internationale des grands barrages, Dix-huitième Congrès des Grands Barrages, Durban. Durban, 543-557 (1994) 